\title{
Urinary Citrate Excretion in Primary Aldosteronism
}

\author{
Ryuji Shioji, Shozo Rikimaru and Hiroshi Ito \\ Department of Internal Medicine (Prof. T. Torikai), \\ Tohoku University School of Medicine, Sendai
}

\begin{abstract}
Urinary citrate output was studied in 5 cases of primary aldosteronism, in 3 of Addison's disease and in 8 of normal subjects. The urinary citrate output was decreased in 4 of 5 cases of primary aldosteronism, and the citrate output could not be normalized by removal of adrenocortical adenoma. In patients with primary aldosteronism citrate excretion was somewhat increased by administration of potassium chloride, but rather decreased by spironolactone. In these putients urinary citrate output could not be correlated with either plasma $\mathrm{CO}_{2}$ content or plasma potassium concentration. The low urinary citrate excretion in primary aldosteronism may not be satisfactorily explained either by direct action of aldosterone on the kidney or by intracellular acidosis.
\end{abstract}

It is known that urinary excretion of citrate is decreased in systemic acidosis and increased in alkalosis without alteration of plasma citrate concentration. ${ }^{1}$ On the other hand, it was found that urinary citrate excretion was decreased in hypokalemic state as in primary aldosteronism, although there was accompanying extracellular alkalosis. ${ }^{2}$ These findings have been explained by a hypothesis that in hypokalemia there is accompanying intracellular acidosis.

The present study is carried out to investigate a possible correlation between urinary citrate excretion and hypokalemia or extracellular alkalosis seen in primary aldosteronism.

\section{Materials and Methods}

A total of 16 human subjects were investigated ( 8 normal controls, 5 with primary aldosteronism and 3 with Addison's disease). Table 1 presents related data in the patients with primary aldosteronism. All of them had hypokalemia. Endogenous creatinine clearance was more than $60 \mathrm{ml} / \mathrm{min}$ in 4 cases. In the remaining one patient there was no azotemia, although the clearance study was not performed. Surgery revealed adrenocortical adenoma in all the 5 patients.

During the study the subjects were put on the ordinary hospital diet. In all subjects daily urinary citrate output was determined over a period of 2 to 5 days.

Received for publication, April 25, 1967. 
TABLE 1. Data in patients

\begin{tabular}{|c|c|c|c|c|c|c|}
\hline \multirow{2}{*}{\multicolumn{3}{|c|}{ Patient }} & \multicolumn{4}{|c|}{ Plasma } \\
\hline & & & \multicolumn{2}{|c|}{$\mathrm{K} \mathrm{mEq} / \mathrm{l}$} & \multicolumn{2}{|c|}{$\mathrm{CO}_{2} \mathrm{mEq} / \mathrm{l}$} \\
\hline Name & Sex & Age & $\begin{array}{c}\text { Pre- } \\
\text { operative }\end{array}$ & $\begin{array}{c}\text { Post- } \\
\text { operative }\end{array}$ & $\begin{array}{c}\text { Pre- } \\
\text { operative }\end{array}$ & $\begin{array}{c}\text { Post- } \\
\text { operative }\end{array}$ \\
\hline S.o. & M & 48 & 2.8 & 3.9 & - & 24.4 \\
\hline M.F. & F & 41 & 2.0 & 3.7 & 35.4 & 25.6 \\
\hline C. 0 . & M & 43 & 1.4 & 4.3 & 36.2 & 24.2 \\
\hline K.N. & $\mathrm{F}$ & 43 & 2.6 & 4.1 & 29.1 & - \\
\hline A.N. & M & 35 & 2.8 & 3.6 & 30.4 & 25.0 \\
\hline
\end{tabular}

In patients with aldosteronism the determinations were also done in a similar way after removal of their adrenal adenoma.

In addition, in 4 aldosteronism cases (except for Case K.N.), urinary citrate excretion was determined during oral administration of spironolactone (Aldactone*

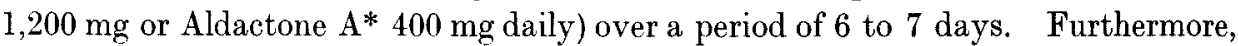
urinary citrate excretion was determined also during oral administration of potassium chloride in a dose of $10 \mathrm{~g}$ daily over a 5 to 9 day period in 4 aldosteronism patients (except for Case A.N.) and in 3 normal controls.

In one patient with Addison's disease, fluctuation of urinary citrate excretion was checked during intramuscular administration of DOCA in a daily dose of $20 \mathrm{mg}$ for 13 days and also during oral administration of dexamethasone $1 \mathrm{mg}$ daily for 12 days.

During the collection of urine samples blood samples were also taken in order to measure potassium level and $\mathrm{CO}_{2}$ content of arterial blood plasma. The collected urine samples were put in a refrigerator after addition of toluene, and when they had to be kept long a portion of the urine samples was put in a deep freezer. Measurement of urinary citrate concentration was performed by the method described by Beutler and Yeh. ${ }^{3}$

Plasma potassium concentration was determined by flame photometry and plasma $\mathrm{CO}_{2}$ content with a Van Slyke manometric apparatus.

\section{Results}

In all 16 subjects, mean daily citrate excretion was calculated (Fig. 1). In normal controls and addisonian patients the mean citrate excretion was more than $200 \mathrm{mg} / 24 \mathrm{hrs}$, whereas in 4 of 5 cases of primary aldosteronism it was less than 100 $\mathrm{mg} / 24 \mathrm{hrs}$. In one aldosteronism patient (Case K.N.) it was normal with a mean excretion of $502 \mathrm{mg} / 24 \mathrm{hrs}$. In the four aldosteronism patients in whom citrate excretion was decreased, the mean citrate excretion tended to increase 20 to 48 days after removal of adrenal adenoma but still remained less than $200 \mathrm{mg} / 24 \mathrm{hrs}$. In one of them (Case S.O.) the mean citrate excretion was as low as $124 \mathrm{mg} / 24 \mathrm{hrs}$

*Supplied by G.D. Searle \& Co. 
with primary aldosteronism

\begin{tabular}{c|c|c|c|c}
\hline \multirow{2}{*}{$\begin{array}{c}\text { Aldosterone } \\
\text { secretion rate } \\
\mu \mathrm{g} / \text { day }\end{array}$} & \multicolumn{3}{|c}{ Urinary citrate excretion mg/day } \\
& \multicolumn{2}{|c}{ Preoperative } & \multicolumn{2}{c}{ Postoperative } \\
\hline 694 & Mean & Range & Mean & Range \\
\hline 415 & 88 & $77-104$ & 124 & 117,131 \\
1,180 & 40 & $36-44$ & 117 & $78-143$ \\
662 & 33 & $30-36$ & 63 & $57-68$ \\
1,158 & 502 & $415-589$ & - & - \\
& 46 & $26-60$ & 47 & $34-54$
\end{tabular}

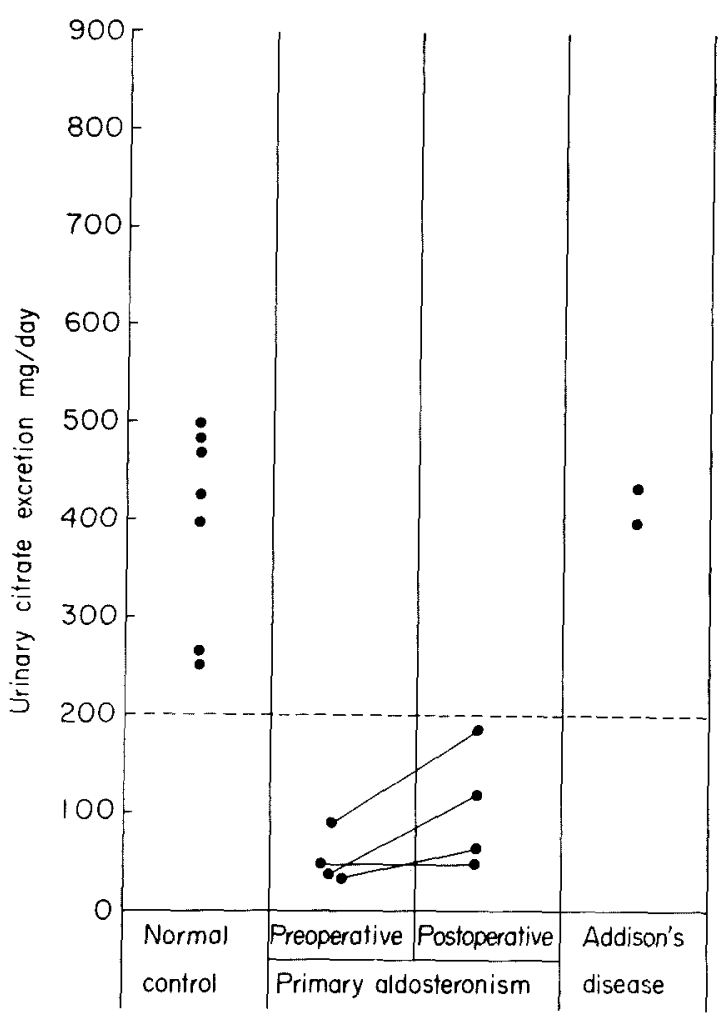

Fig. 1. Urinary citrate excretion in 24 hours in all the subjects examined. Each point represents a mean of repeated measurements done in these subjects.

approximately even 10 months after surgery.

As shown in Fig. 2, citrate excretion was further decreased in the aldosteronism patients during administration of spironolactone, but it gradually began to rise when administration of spironolactone was stopped, reaching finally a much 


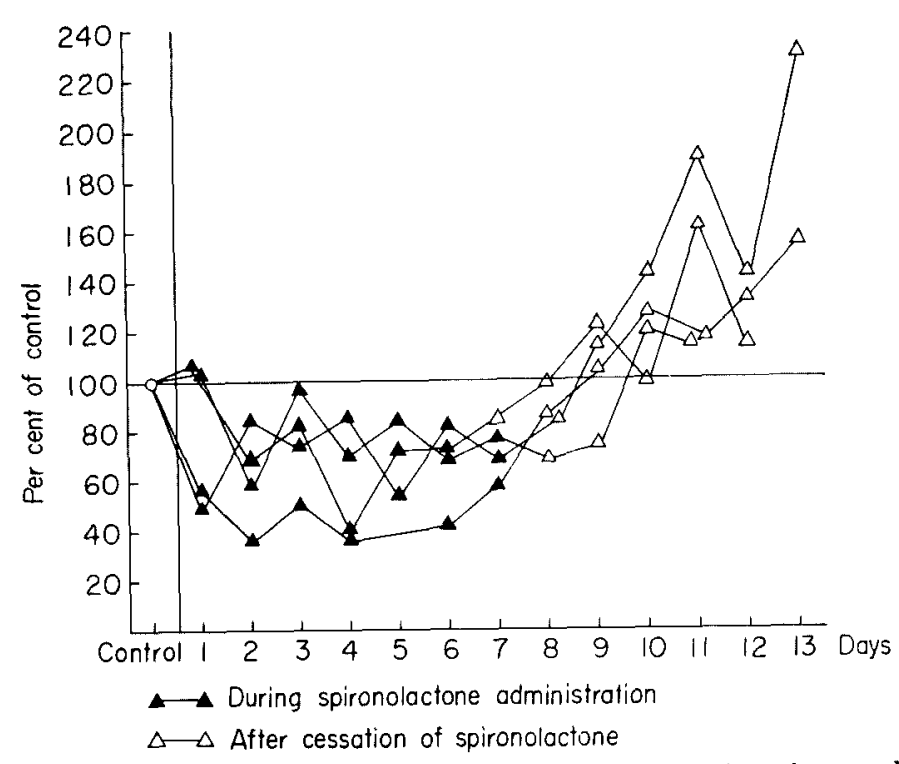

Fig. 2. The effect of spironolactone on urinary citrate excretion in primary aldosteronism patients. Citrate excretion before spironolactone administration was regarded as $100 \%$.

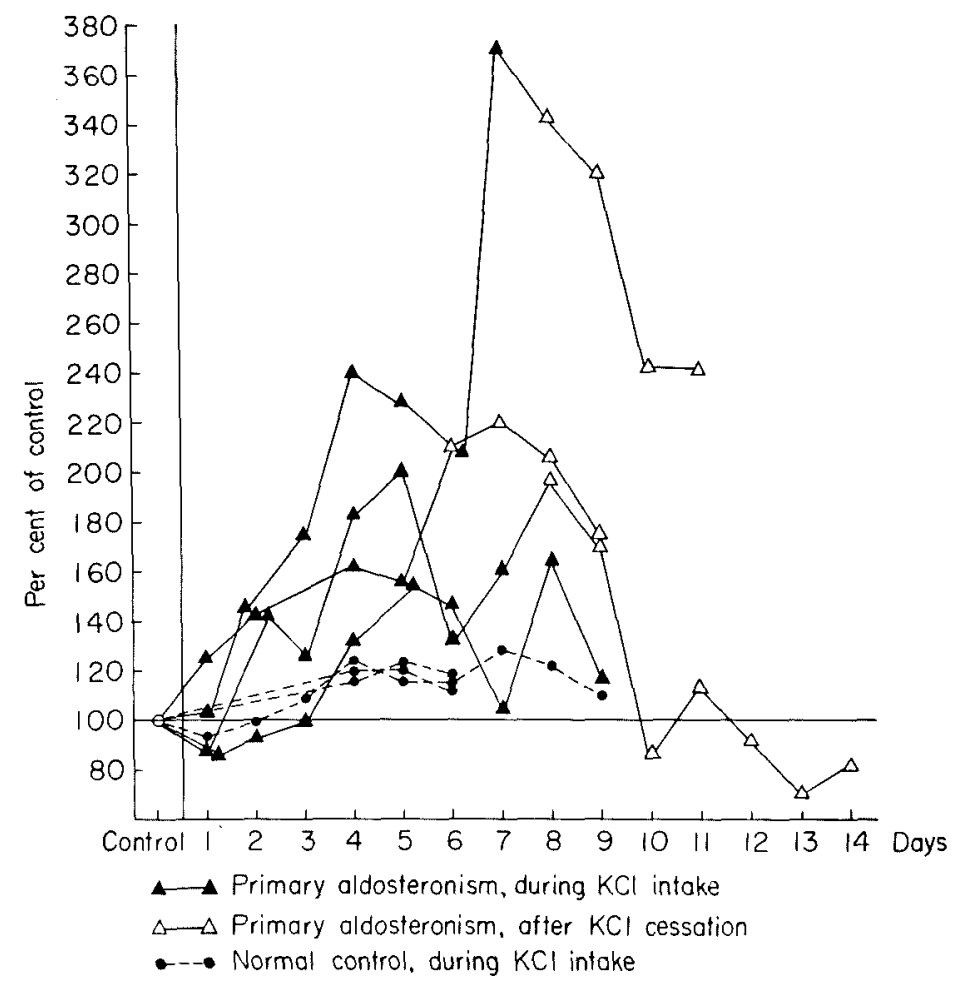

Fig. 3. The effect of potassium chloride on urinary citrate excretion in primary aldosteronism and normal subjects. 
higher level than the pretreatment level.

Fig. 3 shows obvious increase of citrate excretion in the patients with primary aldosteronism by administration of potassium chloride. When the administration was stopped citrate excretion gradually decreased. This was in contrast with the result after spironolactone administration. In normal controls also citrate excretion tended to increase following $\mathrm{KCl}$ administration, but the rise was not significant.

Fig. 4 demonstrates the correlation of urinary citrate excretion with plasma potassium level and with $\mathrm{CO}_{2}$ content determined on the same day in 5 primary aldosteronism patients before any medication, during $\mathrm{KCl}$ or spironolactone administration and after the removal of adenoma. It is seen that citrate excretion was increased during $\mathrm{KCl}$ treatment but it was not correlated with either plasma potassium level or $\mathrm{CO}_{2}$ content.

In addisonian patients citrate excretion remained nearly unaltered even when plasma potassium was reduced to $2.4 \mathrm{mEq} / \mathrm{l}$ by administration of DOCA (Fig. 5).
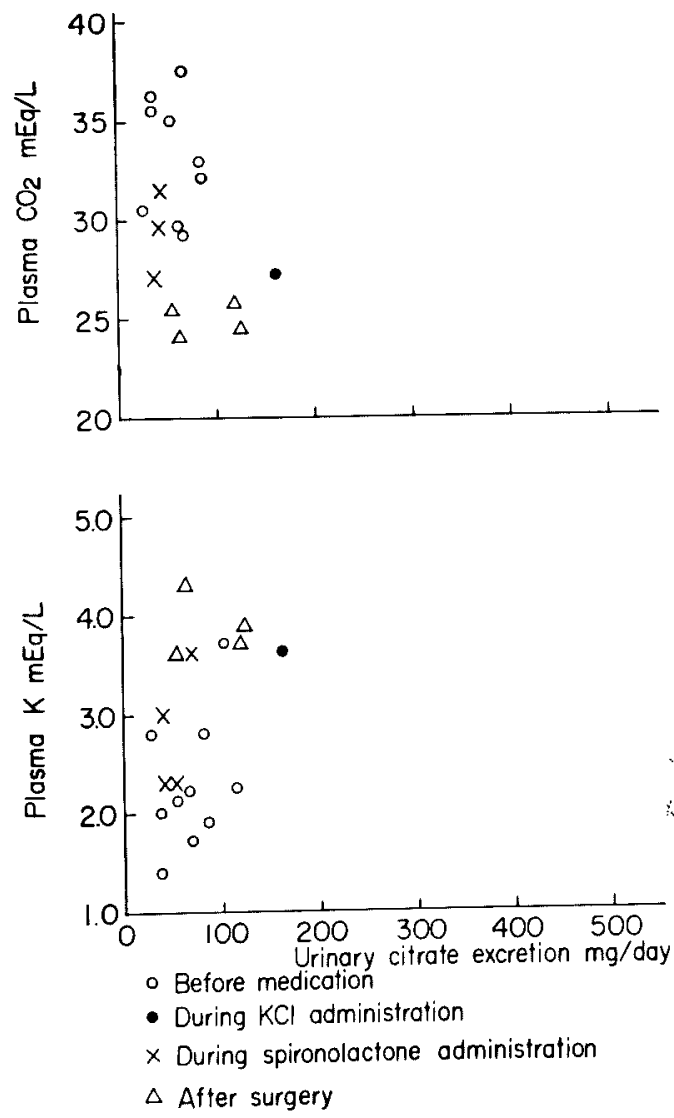

Fig. 4. The relationship of urinary citrate excretion with plasma $\mathrm{CO}_{2}$ content and with plasma potassium level in 5 primary aldosteronism patients. Measurements repeated in the same subjects are represented in the figure without averaging the values, 


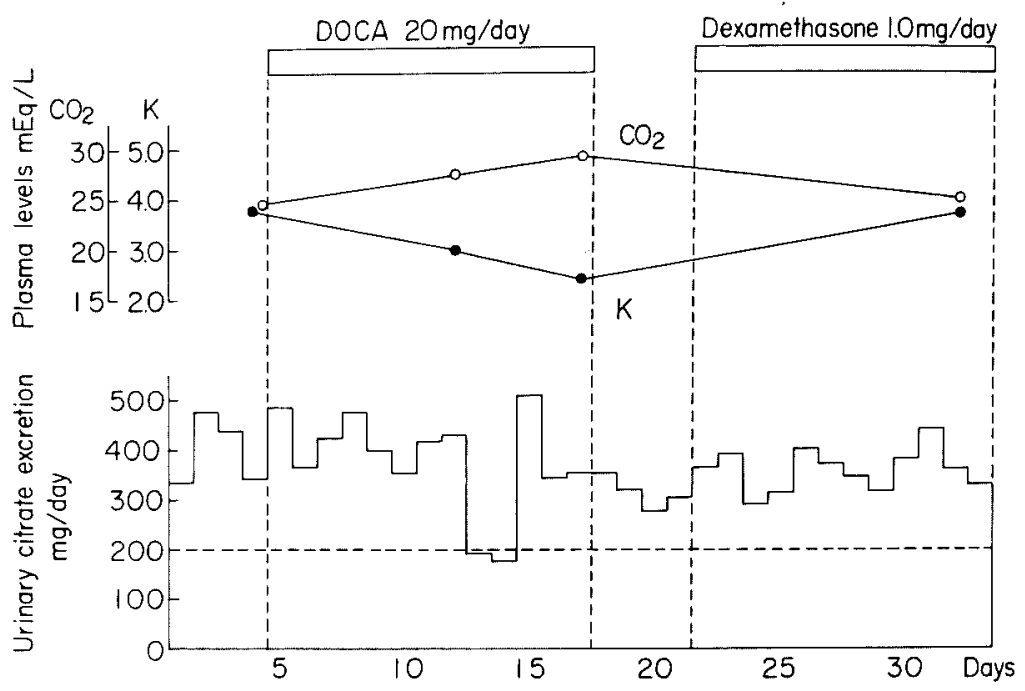

Fig. 5. The effect of DOCA and dexamethasone on urinary citrate excretion, and plasma potassium and plasma $\mathrm{CO}_{2}$ content in addisonian patients.

Dexamethasone also did not cause any significant change in citrate excretion.

\section{Discussion}

Systemic acid-base balance has been believed to be the most important factor to regulate urinary citrate excretion. In an experimental study, Simpson ${ }^{4}$ demonstrated a close relationship between citrate excretion and plasma $\mathrm{HCO}_{3}$. On the other hand, some investigators believe that alkalosis in hypokalemia is produced by transfer of $\mathrm{H}$ ion into the intracellular fluid. ${ }^{5}$ It follows then that there may be a relationship between extracellular alkalosis and intracellular acidosis. Subsequently, it can be expected that the degree of alkalosis in hypokalemia is inversely correlated with urinary citrate excretion.

In the present study of primary aldosteronism patients, however, there is no such apparent correlation as expected by the above hypothesis. It was also found that in our series urinary citrate excretion was still below the normal level even in a sufficiently long period after removal of adrenal adenoma, although plasma potassium level and $\mathrm{CO}_{2}$ content were well within the normal limits. It is difficult to suppose that intracellular acidosis still persists to the end of this period in these patients. It was also seen that citrate excretion was rather decreased during spironolactone administration and increased when the administration was stopped. To explain these observations of ours on the basis of intracellular acid-base balance, it is necessary to suppose that intracellular acidosis is enhanced by spironolactone and, when its administration was stopped, intracellular alkalosis tends to develop. This disagrees with the concept that aldosterone induces intracellular acidosis or that spironolactone is an aldosterone antagonist. Then it does not seem appropriate to believe 
that intracellular acidosis alone is responsible for low citrate excretion in primary aldosteronism.

In recent studies of alkalosis in hypokalemia not only transfer of $\mathrm{H}$ ion into the intracellular space but also some renal involvement was found to be important. ${ }^{6}$ In addition there is an experimental study which does not prove intracellular acidosis in hypokalemic alkalosis. ${ }^{7}$ These reports appear to be compatible with the results of our present study.

It is difficult to believe that low urinary citrate excretion in primary aldosteronism is produced by a direct effect of aldosterone on the kidney, since citrate excretion could be normalized by $\mathrm{KCl}$ administration and did not increase during the spironolactone administration.

Reduced GFR can be responsible for the fact that citrate excretion did not return to the normal level after surgery and that it was decreased during spironolactone administration. In fact, in 3 cases in our study in which kidney function tests were done, GFR was decreased and serum urea nitrogen was increased postoperatively. On the other hand, it has been found that when GFR is above 50 $\mathrm{ml} / \mathrm{min}$ level, urinary citrate excretion is not correlated with GFR. ${ }^{8}$ It was found also that in addisonian patients administration of DOCA or dexamethasone did not cause apparent change in citrate excretion. Therefore, it is questionable that the change in GFR caused by aldosterone might produce the above change in citrate excretion.

On the basis of the present study, reduced citrate excretion in primary aldosteronism cannot be sufficiently explained by postulating either direct effect of aldosterone on the kidney or intracellular acidosis. On the other hand, the possibility that spironolactone has direct action on citrate excretion but not through aldosterone antagonism cannot be excluded.

\section{References}

1) Gordon, E.E. Effect of acute metabolic acidosis and alkalosis on acetate and citrate metabolism in the rat. $J$. clin. Invest., 1963, 42, 137-142.

2) Evans, B.M., MacIntyre, I., MacPherson, C.R. \& Milne, M.D. Alkalosis in sodium and potassium depletion (with especial reference to organic acid excretion). Clin. Sci., 1963, 16, 53-65.

3) Beutler, E. \& Yeh, M.K.Y. A simplified method for the determination of citric acid. J. Lab. clin. Med., 1959, 54, 125-131.

4) Simpson, D.P. Influence of plasma bicarbonate concentration and $\mathrm{pH}$ on citrate excretion. Amer. J. Physiol., 1964, 206, 875-882.

5) Cooke, R.E., Segar, W.E., Cheek, D.B., Coville, F.E. \& Darrow, D.C. The extrarenal correction of alkalosis associated with potassium deficiency. J. clin. Invest., 1952, 31, 798-805.

6) Struyvenberg, A., de Graeff, J. \& Lameijer, L.D.F. The role of chloride in hypokalemic alkalosis in the rat. $J$. clin. Invest., 1965, 44, 326-338.

7) Miller, R.B., Tyson, I. \& Relman, A.S. $\mathrm{pH}$ of isolated resting skeletal muscle and its relation to potassium content. Amer. J. Physiol., 1963, 204, 1048-1054.

8) Laake, H. \& Hovig, T. The renal excretion of citric acid. Acta med. scand., 1962, 172, $327-330$. 